\title{
Abdelhamid H Elgazzar, Ismet Sarikaya (Eds): Nuclear Medicine Companion. A Case-Based Practical Reference for Daily Use
}

\author{
Springer Nature, 2018. ISBN 978-3-319-76,155-8
}

\author{
Luigi Mansi $^{1}$
}

Published online: 20 June 2019

(C) Springer-Verlag GmbH Germany, part of Springer Nature 2019

\section{Nuclear Medicine Companion. A Case-Based Practical} Reference for Daily Use is edited by Abdelhamid H. Elgazzar, Professor and Chairman of the Department of Nuclear Medicine at the University of Kuwait, and Ismet Sarikaya, Associate Professor at the same University.

This publication belongs to the category that I call "desk books", including volumes to keep handy in any nuclear medicine diagnostics setting. Consisting of 341 pages, it includes more than 250 case reviews and is enriched by figures chosen on the basis of an easy explanation of the scintigraphic procedure. This means that the majority of the patients represented are paradigmatic, although some rarer cases are presented as well.

The editorial structure is based on 11 chapters, 8 of which concern clinical systems: (1) endocrine, (2) pulmonary, (3) cardiovascular, (4) skeletal, (5) genitourinary, (6) digestive, (7) hepatobiliary, and (8) central nervous system. Chapters 9 and 10 consider inflammation and oncology, respectively. The 11 th and final chapter is dedicated to miscellaneous conditions.
Each chapter starts with a description of normal patterns, acquired under common and uncommon conditions, to understand when and how the procedures should be performed. In the second part, the diagnostic role of scintigraphic techniques is defined through the presentation of clinical cases in which they appear useful, as well as the presence of alternative procedures. In addition, normal patterns on relevant morphologic modalities are documented in an appendix.

Not being an atlas and not intending to cover all possible indications of nuclear medicine, this publication aims to present the most widespread and many of the least used methods in nuclear medicine to answer most of the questions asked in daily clinical practice.

Mainly directed to students, trainees and technologists in nuclear medicine and radiology (the last if practicing the field), this book can also be of interest to practitioners, who may find easy and fast information helpful for their routine work. Therefore, this volume could find a worthy place in the drawer or desk of every nuclear medicine diagnostic lab.
Luigi Mansi

mansi.luigi@libero.it

1 Interuniversity Research Center for Sustainability (CIRPS), Naples, Italy 